\title{
Willingness of future teachers to apply innovative productive teaching methods to form a healthy lifestyle in preschoolers
}

\author{
Elena Egorova ${ }^{1, *}$ \\ ${ }^{1}$ Don State Technical University, Gagarin sq., 1, Rostov on Don, 344003, Russia
}

\begin{abstract}
The goal of the study is to investigate the willingness of future teachers to apply innovative productive teaching methods in their direct work. Future teachers took part in the written survey $\left(\mathrm{N}_{0}=141\right)$, students of other specialities and established professionals $\left(\mathrm{N}_{1}=\mathrm{N}_{2}=28\right)$. Fisher's $\varphi$ test, Pearson's correlation coefficient, biserial correlation coefficient, Kendall's $\tau$ correlation coefficient, Student's t-test $(p \leq 0.01)$ were used to statistically evaluate the resultsIt is shown that future teachers from the proposed options choose mainly reproductive methods, and freely formulate informative methods. The most significant differences were revealed between the samples of future teachers and "adults" who do not have pedagogical training, which indicates the choice of methods not based on knowledge in the professional sphere, but on the basis of everyday ideas characteristic of this generation. It can be concluded that future teachers are really not ready to apply innovative productive methods in their practice, preferring more traditional informative and reproductive ones. This poses the task of finding ways to introduce into pedagogical practice those methods, theoretical reasoning about which is oversaturated in modern scientific and educational discourse.
\end{abstract}

\section{Introduction}

At present, the scientific community is actively discussing the issues of modernization of education. It is in this formulation of the question that discourse is characteristic of countries and regions that, at a certain point in their historical development, have made a decision about Westernization or Americanization. These are Latin America (first of all, Brazil), the states of the post-Soviet space (mainly works of a similar orientation are published by authors from Russia, Ukraine and Kazakhstan), Asia (China and South Korea).

The problems of improving the quality of education are discussed $[1 ; 2]$, issues of effective management and administrative principles of a successful educational process [2; 3], new training programs, principles for the formation of new specialties and their compliance with market demands, the specificity of certain areas of training, which determines certain features of the modernization process $[4 ; 5]$, digitalization of the educational process and its impact on the principles of communication between a teacher

Corresponding author: filonovaei@ya.ru 
and a student [1-8]. Also, as a separate area of research into the modernization of education, one can single out historiographic works that have a descriptive or analytical nature (for example, [9]), the main purpose of which is to find successful and identify failed approaches to modernizing education. In general, we can state that both the modernization of education in these regions and the study of modernization processes are initiated and carried out from above.

For European and American studies, the concept of "modernization of education" is not typical in principle. Any questions of improving the quality and effectiveness of teaching are raised at the technological level associated with practice and direct contact between the teacher and the student. It also discusses the problems of digitalization and especially - the influence of the Internet on the learning process [10-11]. In foreign publications, issues of productivity of certain teaching methods are widely discussed [12-13]. In general, the tendency to ascribe the property of productivity to any phenomenon that arises in the learning process appears quite clearly. As productive components of the educational process, not only creativity [14], teamwork or design methods [15], play [16] are considered, but also confusion, mistakes, failures [17-18].

Thus, in the Western scientific discourse, the issues of improving the quality and efficiency of education are considered from a different angle and from the standpoint of a different approach - from below. In this case, the main object is the direct learning process, and not its organization, technical equipment, documentation, adjustment to the needs of the market, etc. Works in this area always contain specific conclusions about the productivity or non-productivity of a particular pedagogical method, which makes it possible to give completely definite recommendations for the use of certain methods in the educational process.

Among the publications of the modernization discourse, there are also many works devoted to assessing the effectiveness of changes taking place in the education system. If we talk about the studies that have been carried out in Russia in recent years, then we can state that, although some positive shifts are observed, in general, the modernization of education can not be called successful: the indicators of learning productivity do not increase or increase very insignificantly - within the limits of random fluctuations.

Accordingly, the question is natural: why are the huge efforts aimed at modernizing education not giving the desired effect?

In the broadest sense, our hypothesis is that the absence of visible results of education modernization is due to the fact that the changes initiated from above do not affect the lower and basic layers of the educational process - the teacher's work itself, as well as the principles of communication between the teacher and the student.

In a narrower sense, we assume that the teaching staff, while declaring their commitment to innovative principles of teaching and the modern paradigm of education, are not ready in practice to apply innovative methods in working with students.

Based on the foregoing, we formulate the goal of this article as follows: to study the willingness of future teachers to apply innovative productive teaching methods in their direct work.

Comments should be made regarding the concept of "productive methods". We use this concept in the sense in which it is included in the domestic pedagogy, that is, as methods aimed at initiating the creative activity of students and their ability to independently create new algorithms for solving the problems they face. Productive teaching methods correlate with reproductive methods, which are aimed at developing students' ability to independently solve problems according to a given pattern based on the reproduction of a certain model and sequence of actions, and are opposed to informative (illustrative, demonstrating, explanatory) methods that only allow gaining knowledge and ideas about subject, but not master the skills of working with it. 


\section{Materials and methods}

The research presented in this article is part of a broader study on healthy lifestyles among preschoolers. The study was conducted in the format of a written survey, which included a section on methods of forming a healthy lifestyle among preschoolers. The section contained both open-ended questions, to which respondents could answer in a free form, and questions with a list of answers, from which respondents were asked to choose one or several options. At the same time, there was always an opportunity to supplement the answer if, in the opinion of the respondent, the proposed options were not complete, accurate or comprehensive.

The first question on which this article is based contained answer options - 26 different methods of forming a healthy lifestyle in preschoolers. Of these, 11 are informative and demonstrative, 8 are reproductive and 7 are productive methods, appropriate for the age of students. The respondents were asked to mark all the methods that are applicable to the formation of a healthy lifestyle in preschoolers, and then rank the five most significant of them $(1$ - the most significant, 5 - the least significant; value 6 was assigned to methods that were not included in the ranking list, but applicable methods, 7 - methods not marked as applicable). It was also suggested to supplement the list if necessary. Based on the ranking, the 5 most significant methods were selected, with which further analytical work was carried out.

In the open-ended question, the respondents were asked to describe the methods by which they would make preschoolers understand what health and disease are, how to maintain health and avoid diseases. The proposed methods were evaluated on a four-point system, where 0 is the absence of a method, 1 is an informing or demonstrative method, 2 is a reproductive method, 3 is a productive method, and then the scores were added.

The results obtained by the methods of forming a healthy lifestyle were correlated with the data of testing for valeological competence and a survey about personal experience of forming a healthy lifestyle (as a student). In assessing the latter factor, the same scale was used as in the open-ended question on methods. As an additional factor, the analysis included data on the respondents' subjective assessment of their lifestyle as healthy or not.The study involved DSTU students studying in the training area 440301 - Pedagogical education (N0 = 141) - the main sample, as well as students studying in non-pedagogical areas $(\mathrm{N} 1=28)$ and "adults" - people over 29 years old with non-pedagogical specialties and those in employment $(\mathrm{N} 2=28)$. It was originally intended to treat these two groups as one. However, the initial analysis of the data showed that in the first and second control groups, the results differ significantly.

Participation in the survey was voluntary. The survey was conducted in 2019.

The data obtained as a result of the survey were subjected to qualitative and quantitative analysis. The answers to open-ended questions were studied using content analysis: certain concepts were identified that could be expressed in different terms for different respondents. Mathematical data processing was carried out using the statistical tools of the open application LibreOffice 5.4 Calc and the R-Portable_3.6.3 mathematical package. To assess the differences, the nonparametric Fisher $\varphi$ test was used $(p \leqslant 0.01)$. Pearson's correlation coefficient was used to assess the linear correlation of variables with a distribution close to normal. To assess the correlation of data series expressed in the interval scale and in the dichotomous scale, a biserial correlation coefficient was used with an additional assessment of the significance of the result using the Student's t-test. To analyze the correlations of data series that do not have a normal distribution, the Kendall correlation coefficient $\tau$ was used with a check using the Student's t-test.

\section{Results}




\subsection{Primary data analysis}

Primary data analysis showed that most of the variables considered in the study on the studied samples have a non-normal distribution, which determines the choice of nonparametric criteria for further work with data.

After the primary processing of the data on the question with answer options and the evaluation of the ranked methods, for each group of subjects, five most significant methods were identified. These methods are summarized in Table 1.

Table 1. The most significant methods of forming a healthy lifestyle (according to the survey respondents).

\begin{tabular}{|c|c|c|}
\hline № & Methods & Category \\
\hline \multicolumn{3}{|c|}{ Main sample } \\
\hline 1 & ${ }^{*}$ Sports activities & Reproductive \\
\hline 2 & "Practical organization of personal hygiene & Reproductive \\
\hline 3 & ${ }^{* \#}$ Practical organization of proper nutrition & Reproductive \\
\hline 4 & ${ }^{* *}$ Practical organization of the daily routine & Reproductive \\
\hline \multirow[t]{2}{*}{$5-6$} & *Explanatory conversations about a healthy lifestyle & Informing \\
\hline & Games dedicated to distinguishing between good and bad & Productive \\
\hline \multicolumn{3}{|c|}{ Control group 1 (students) } \\
\hline 1 & ${ }^{*}$ Sports activities & Reproductive \\
\hline 2 & *Practical organization of proper nutrition & Reproductive \\
\hline 3 & Explanatory conversations about a healthy lifestyle & Informing \\
\hline \multirow[t]{2}{*}{$4-5$} & "Practical organization of the daily routine & Reproductive \\
\hline & Informational activities for the prevention of bad habits & Informing \\
\hline \multicolumn{3}{|c|}{ Control group 2 ("adults") } \\
\hline 1 & "Practical organization of personal hygiene & Reproductive \\
\hline \multirow[t]{2}{*}{$2-3$} & Gymnastics & Reproductive \\
\hline & "Practical organization of the daily routine & Reproductive \\
\hline 4 & "Practical organization of proper nutrition & Reproductive \\
\hline 5 & $\begin{array}{l}\text { Acquaintance with knowledge about the human body in a playful } \\
\text { way }\end{array}$ & Productive \\
\hline
\end{tabular}

Note to Table 1:* - methods that are in the top five most significant both in the main sample and in the 1st control group; \# - methods that are in the top five most significant both in the main sample and in the 2 nd control group; for the main sample, not 5 , but 6 methods are given, since the last two received the same rank in the sample. Further research also looked at these six methods.

As we can see, in the main sample and in the 2nd control group, one productive method fell into the five most significant methods. In the main sample and in the 1st control group, the top five got one informing method. The bulk of the most significant methods were reproductive methods.

We also note that for all three groups, the first methods in the list had a significant gap from all subsequent ones, while the difference between the other four (five in the main sample) methods was extremely insignificant. In addition, we believe that "sports" for the main sample and the 1 st control group are equivalent to "gymnastics" for the 2 nd control 
group, and here we are talking about differences in vocabulary rather than a fundamental difference in approaches.

In the ranked full list for the main sample, one productive method was in the top ten. The majority of the respondents not only did not indicate productive methods as the most significant, but did not mark them at all as applicable in pedagogical work on a given topic.

It should be borne in mind that, although the survey offered a list of methods from which the most significant should be selected, it was also proposed to supplement the list if necessary. None of the respondents took advantage of this opportunity.

The data of the open-ended question were processed as follows: the formulated method was assessed on a scale from 0 to 3 for each of the two components of the answer (about health and about disease). Thus, the total score from 0 to 2 corresponds to informative methods, from 2 to 4 - reproductive, from 4 to 6 - productive. The results are presented in Table 2 .

Table 2. Average ratings of methods proposed by respondents in an open-ended question.

\begin{tabular}{|l|l|c|}
\hline \multicolumn{1}{|c|}{ Group } & Average rating & Corresponding method \\
\hline Main sample & 1,9 & Informing \\
\hline 1 control group & 2,0 & Informing \\
\hline 2 control group & 2,7 & Reproductive \\
\hline
\end{tabular}

As we can see, a shift towards productive methods is observed in the control group of "adults", and not among future teachers. Moreover, future teachers' score is even lower than that of students in other areas of training.

Table 3 presents the main statistical characteristics of the results obtained for all three samples according to the most significant methods proposed to choose from (a total of 9 methods that fell into the first five samples), and the results of evaluating methods freely formulated by the respondents.

Table 3. Statistical indicators of the results obtained for three samples.

\begin{tabular}{|c|c|c|c|c|}
\hline Sample & Mode & Median & Average* & $\begin{array}{l}\text { Standard } \\
\text { deviation" }\end{array}$ \\
\hline \multicolumn{5}{|c|}{$\begin{array}{c}\text { Practical gymnastics (assessment of significance from } 1 \text { - the most significant method, to } 7 \text { - ar } \\
\text { insignificant method, an inapplicable method) }\end{array}$} \\
\hline $\mathrm{N}_{0}$ & 7 & 7 & 6.2 & 1.4 \\
\hline $\mathrm{N}_{1}$ & 7 & 7 & 6 & 1.6 \\
\hline $\mathrm{N}_{2}$ & 1 & 5 & 4 & 2.4 \\
\hline \multicolumn{5}{|c|}{$\begin{array}{c}\text { Sports activities (assessment of significance from } 1 \text { - the most significant method, to } 7 \text { - an } \\
\text { insignificant method, inapplicable method) }\end{array}$} \\
\hline $\mathrm{N}_{0}$ & 1 & 2 & 3.3 & 2.4 \\
\hline $\mathrm{N}_{1}$ & 1 & 1 & 3.1 & 2.6 \\
\hline $\mathrm{N}_{2}$ & 7 & 7 & 6.7 & 0.46 \\
\hline \multicolumn{5}{|c|}{$\begin{array}{l}\text { Practical organization of the daily routine (assessment of significance from } 1 \text { - the most } \\
\text { significant method, to } 7 \text { - an insignificant method, an inapplicable method) }\end{array}$} \\
\hline $\mathrm{N}_{0}$ & 7 & 6 & 5.2 & 2.2 \\
\hline $\mathrm{N}_{1}$ & 7 & 7 & 5.9 & 2.1 \\
\hline
\end{tabular}




\begin{tabular}{|l|l|l|l|l|}
\hline $\mathrm{N}_{2}$ & 3 & 3 & 4 & 1.9 \\
\hline \multicolumn{5}{|c|}{$\begin{array}{r}\text { Practical organization of personal hygiene (assessment of significance from 1 - the most } \\
\text { significant method, to 7 - an insignificant method, inapplicable method) }\end{array}$} \\
\hline $\mathrm{N}_{0}$ & 7 & 6 & 4.6 & 2.4 \\
\hline $\mathrm{N}_{1}$ & 7 & 7 & 6.3 & 1.8 \\
\hline $\mathrm{N}_{2}$ & 2 & 3 & 3.1 & 1.6 \\
\hline \multicolumn{4}{|c|}{$\begin{array}{l}\text { Practical organization of proper nutrition (assessment of significance from 1 - the most } \\
\text { significant method, to 7 - insignificant method, inapplicable method) }\end{array}$} \\
\hline $\mathrm{N}_{0}$ & 7 & 6 & 4.9 & 2.3 \\
\hline $\mathrm{N}_{1}$ & 7 & 6 & 5 & 2.1 \\
\hline $\mathrm{N}_{2}$ & 6 & 6 & 4.9 & 2.3 \\
\hline
\end{tabular}

Explanatory conversations about healthy lifestyle (assessment of significance from 1 - the most significant method, to 7 - an insignificant method, inapplicable method)

\begin{tabular}{|l|l|l|l|l|}
\hline $\mathrm{N}_{0}$ & 7 & 6 & 5.6 & 1.7 \\
\hline $\mathrm{N}_{1}$ & 7 & 7 & 5.4 & 2.2 \\
\hline $\mathrm{N}_{2}$ & 7 & 7 & 6.9 & 0.36 \\
\hline
\end{tabular}

Informational measures for the prevention of bad habits (assessment of significance from 1 the most significant method, to 7 - insignificant method, inapplicable method)

\begin{tabular}{|l|l|l|l|l|}
\hline $\mathrm{N}_{0}$ & 7 & 6 & 6 & 1,4 \\
\hline $\mathrm{N}_{1}$ & 7 & 7 & 5,9 & 2,1 \\
\hline $\mathrm{N}_{2}$ & 7 & 7 & 6,6 & 0,74 \\
\hline
\end{tabular}

Acquaintance with knowledge about the human body in a playful way (assessment of significance from 1 - the most significant method, to 7 - an insignificant method, inapplicable method)

\begin{tabular}{|l|l|l|l|l|}
\hline $\mathrm{N}_{0}$ & 7 & 7 & 6,4 & 0,88 \\
\hline $\mathrm{N}_{1}$ & 7 & 7 & 6,1 & 1,8 \\
\hline $\mathrm{N}_{2}$ & 6 & 6 & 5,1 & 1,8 \\
\hline
\end{tabular}

Games dedicated to distinguishing between good and bad (in nutrition, in behavior, etc.) (significance score from 1 is the most significant method, to 7 is an insignificant method, an inapplicable method)

\begin{tabular}{|l|l|l|l|l|}
\hline $\mathrm{N}_{0}$ & 6 & 6 & 5,6 & 1,4 \\
\hline $\mathrm{N}_{1}$ & 7 & 7 & 6,9 & 0,36 \\
\hline $\mathrm{N}_{2}$ & 6 & 6 & 5,7 & 0,71 \\
\hline
\end{tabular}

Qualitative assessment of the methods proposed in the open-ended question (from 0 - no method, to 5-6 - productive method)

\begin{tabular}{|l|l|l|l|l|}
\hline $\mathrm{N}_{0}$ & 2 & 2 & 1,9 & 1,3 \\
\hline $\mathrm{N}_{1}$ & 2 & 2 & 2 & 1,5 \\
\hline $\mathrm{N}_{2}$ & 3 & 3 & 2,7 & 1,3 \\
\hline
\end{tabular}

Note to Table $3: *$ - the column contains values rounded to two significant figures. 
Evaluation of differences using Fisher's $\varphi$ test $(p \leqslant 0.01)$ between the main sample and the first control group, as well as between the main sample and the second control group in free formulation of methods, gave the following results:

- significant differences between the main and the first control group were revealed in the choice of one informing and mixed informing and reproductive methods: future teachers more often offered only one method instead of two, which was informative, as well as one informing and one reproductive method, while students of other areas of training either they did not offer any methods at all, or they offered two methods of the same quality (with a predominance of informative methods);

- significant differences between the main sample and the second control group were revealed in the same elections, as well as in the choice of the informing method in both cases: at the same time, "adults" were much more likely to offer two different methods (informative and reproductive) than future teachers, and less often to offer two informative methods. At first glance, it seems that "adults" were more likely to suggest two reproductive methods, but statistical analysis did not reveal significant differences even at $\mathrm{p}$ $\leqslant 0.05$.

Analysis of differences using Fisher's $\varphi$ test $(p \leqslant 0.01)$ in assessing the significance of the methods proposed for ranking (statistical indicators were considered only for 9 methods included in the top five most significant in three groups) revealed statistically significant differences between the main sample and the first control sample. group, and between the main sample and the second control group. Fisher's test generally had higher values for the second pair. The analysis showed that:

1. Practical gymnastics

a) future teachers more often included the method in the list of significance, but at the same time gave the lowest mark, students of other directions more often did not consider the method applicable at all;b) "adults" much more often assessed this method as the most significant and included it in the list of applicable methods than future teachers.

2. Sports activities

a) Respondents from the first control group more often gave an average assessment of the significance of the method due to higher, but not the highest, assessments of significance, while future teachers have a pronounced surge in high assessment of the significance of the method and a relatively even distribution of all other assessments;

b) the respondents from the second control group often did not include the method in the list of applicable ones at all, while future teachers put it in first place in terms of importance.

3. Practical organization of the daily routine

a) Most of the respondents from the first control group did not include this method in the list of applicable ones, while more than half of the future teachers included it in this list, but their significance was ambiguously assessed;

b) among "adults", not a single respondent excluded this method from the list of applicable ones.

4. Practical organization of personal hygiene

a) in the main sample and the first control group, significant differences were found in relation to the inclusion of the method in the list of applicable methods and the highest assessment of its significance: more than half of the teachers included it in the list and almost half in the top five most significant, and students from other areas of training or did not include it to the list $(85.7 \%$ ), or assessed the significance as low;

b) all respondents of the second control group included the method in the list of applicable ones and $90 \%$ gave an average or high assessment of its significance, while in the main sample, the distribution of significance assessments (among those who included the method in the list of acceptable ones) is more even. 


\section{Practical organization of proper nutrition}

a) no significant differences were found between the main sample and the first control group at the $p \leqslant 0.01$ level; at the $p \leqslant 0.05$ level, differences were revealed in the high and medium estimates of the significance of the method: the second control group did not give the highest estimates of the significance in general and gave a relatively larger number of average estimates of the significance;

b) "adults" rated the significance and applicability of this method lower than future teachers; thus, more than half of the respondents in the second control group did not include the method in the list of applicable ones, rated it as insignificant or having the lowest significance.

6. Explanatory conversations about a healthy lifestyle

a) in the assessment of this method in the main sample, there is a pronounced bias towards insignificance and inapplicability, and in the first control group there are peaks at the point of rejection of the method and at the point of high, but not the highest assessment of significance;

b) the second control group qualified the method as inapplicable or applicable, but insignificant, while the main sample considered it applicable and almost a third gave a high or medium assessment of its significance.

7. Informational measures for the prevention of bad habits

a) $71.4 \%$ of the respondents in the first control group did not include the method in the list of applicable ones, while less than half of future teachers made the same decision; however, among students of non-pedagogical specialties, there were those who gave the highest rating to the significance of the method, while among future teachers, its significance received a low or medium rating;

b) among "adults" the same percentage of those who rejected the method as in the first control group, however, the rest gave it the lowest significance rating - even lower than the respondents from the main sample.

8. Acquaintance with knowledge about the human body in a playful way

a) more than half of future teachers and more than $70 \%$ of students of other specialties did not include this method in the list of applicable ones, however, among the respondents of the main sample, the majority of those who nevertheless noted the method as applicable rated it as insignificant, and half of the respondents from the first control group who included the method as applicable, rated it as highly significant;

b) among the respondents of the second control group, only $14 \%$ did not include the method in the list of applicable ones; among the rest, there is a slightly greater shift towards a high assessment of the significance of the method than in the main sample, although on average the assessment still remains extremely low.

9. Games dedicated to distinguishing between useful and harmful

a) the majority of future teachers included the method as acceptable, although they gave a low assessment of its significance, but the first control group (82\%) did not include the method in the list of applicable ones;

b) unlike the respondents of the main sample, all respondents from the second control group included the method in the list of acceptable ones, but they rated its significance rather low.

\subsection{Correlation analysis of the main sample data}

We investigated the correlations between the assessments of the importance of methods for the formation of a healthy lifestyle in preschoolers $(6$ most significant methods in this sample), as well as the values characterizing the choice of methods in the open-ended 
question, and valeological competence, personal experience of forming a healthy lifestyle as a student, subjective assessment of one's own lifestyle as healthy or unhealthy.

The results of testing for valeological competence, the characteristics of the methods proposed in the open-ended question, and the characteristics of personal experience in the formation of a healthy lifestyle have a distribution close to normal, which made it possible to apply the Pearson's correlation coefficient to these variables. No significant linear correlation was found between personal experience and the choice of method in the openended question. When evaluating the data by a graphical method, there were also no grounds for assuming the presence of a correlation. A linear direct correlation was found between the test results for valeological competence and the formulation of methods in the open-ended question, which was significant for the level of $p \leqslant 0.05$.

Subjective assessment of one's own lifestyle is expressed in a dichotomous scale. Therefore, to analyze the correlations of this factor with the choice of methods for the formation of a healthy lifestyle by future teachers, the biserial test was used with verification by means of the Student's t-test.

The analysis did not reveal a significant correlation between the respondents' subjective assessment of their lifestyle as healthy or unhealthy and the quality of the methods proposed in the answers to the open-ended question. Analysis of the data using a graphical method also does not give grounds to assume the presence of a correlation.

When analyzing the correlation between the subjective assessment of the lifestyle and the assessment of the significance of the proposed methods (in the question with a set of answers), the following indicators were identified:

- no significant correlations were found with the assessment of the significance of the method of practical organization of personal hygiene;

- at the level of $p \leqslant 0.05$, correlations were revealed with the assessment of the significance of the methods of practical organization of the daily routine, explanatory conversations about a healthy lifestyle and games dedicated to distinguishing between useful and harmful;

- at the level of $p \leqslant 0.01$, correlations were found with the assessment of the significance of sports methods and the practical organization of proper nutrition In all cases, except for evaluating the methods of practical organization of the daily routine and the practical organization of proper nutrition, the respondents who believe that they lead a healthy lifestyle rated the significance of the corresponding methods higher.

To analyze the correlations between valeological competence and the respondents' assessment of the significance of the methods from the proposed list, as well as between personal experience of forming a healthy lifestyle (as a student) and the assessment of the significance of the methods, the Kendall's correlation coefficient $\tau$ was used with checking the statistical significance using the Student's t-test. The choice of the method is due to the fact that the estimates of the significance of the methods do not have a normal or close to normal distribution.

The analysis showed no significant correlations for these data series, except for the ratio of valeological competence with the assessment of the significance of the method "Games dedicated to distinguishing between useful and harmful". In this case, the correlation coefficient was $\tau=0.17$, which has statistical significance for the level $p \leqslant 0.01$. Figure 1 shows a graph of the relationship between these variables. We can see that with low valeological competence, respondents gave a low assessment of the significance of the method or did not include it at all in the list of acceptable ones. Then, with an increase in competence, the assessment of the significance of the method also increased for some time. But after passing the peak at 4 points for the test for valeological competence, with a further increase in competence, the assessment of the significance of the method decreases again. 


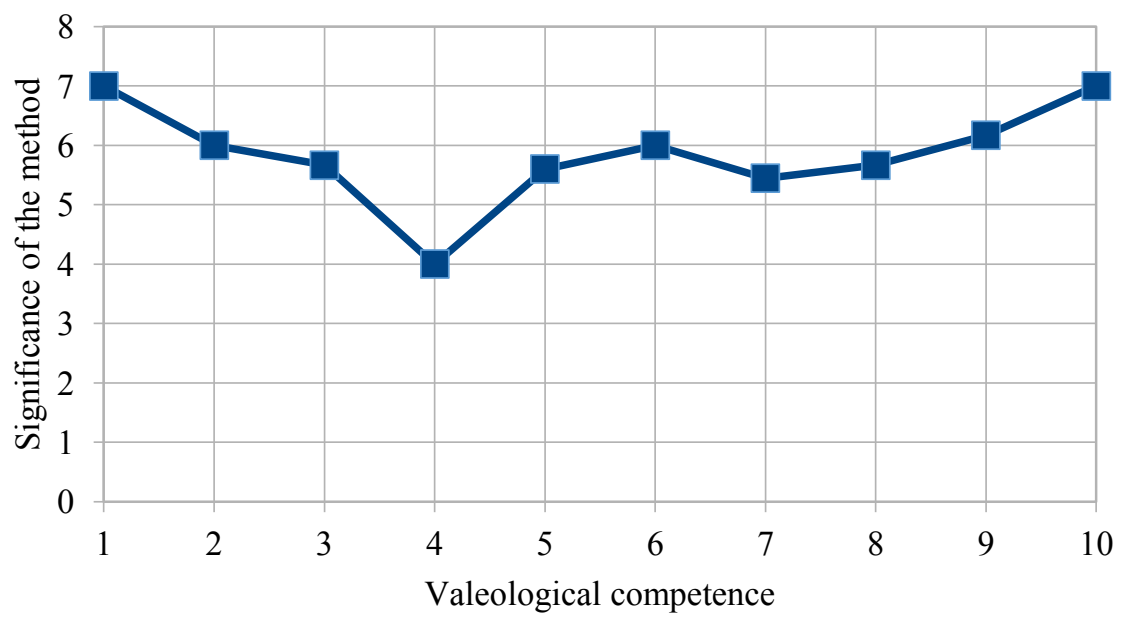

Fig. 1. The graph of the relationship between the level of valeological competence and the assessment of the significance of the method "Games dedicated to distinguishing between useful and harmful" (1 - the most significant, 7 - inapplicable method). The graph is compiled on the basis of the average values of the assessments of the significance of the method for respondents who received a certain point for the test for valeological competence

\section{Discussion}

Based on the above research results, we can consider the hypothesis that future teachers are not ready to apply innovative productive methods in pedagogical practice as confirmed. This is evidenced, firstly, by the choice of predominantly reproductive and informative methods from the proposed list of methods of various qualities and the assessment of these methods as the most significant; secondly, lack of initiative and creativity, which manifests itself in ignoring the opportunity to supplement the list of proposed methods. This hypothesis is also supported by the results of an open-ended question in which informative methods were proposed, while not only productive, but even reproductive methods were not mentioned by the majority of the respondents in the main sample.

Comparison of the results for the main sample with the results obtained for the control groups allows us to assert that the choice and formulation of methods, their quality, is largely influenced not by professional training, but by the age and life experience of the respondents. This is evidenced by the significantly greater similarity of the results for the main sample (students of the pedagogical direction of training) and the first control group (students of other areas of training) than the main sample and the second control group ("adults"). The choice of methods is carried out by the respondents not on the basis of knowledge in the professional sphere, but on the basis of everyday ideas characteristic of this generation.

However, the correlation analysis only partly confirms the assumption made about the connection between the choice of method and the respondent's life experience: no correlations were found between the quality of the methods to which the respondents themselves were exposed at the stage of training and education, and the methods that they are ready to use in their pedagogical practice. At the same time, correlations of varying degrees of statistical significance exist between the choice of methods and the respondents' subjective assessment of their lifestyle as healthy or unhealthy. That is, personal experience 
and way of thinking are somehow connected with the choices that teachers make in the professional field.

Of greatest interest is the fact that valeological competence, that is, the level of knowledge in a certain area, very weakly correlates with the choice of teaching methods in this area. Accordingly, it must be recognized that being well informed and proficient in their subject does not at all guarantee that the educator will use innovative, productive methods in their work and that their working methods will be effective. Accordingly, in order to introduce innovative components into educational practice, it is necessary to train future teachers in the use of these innovative components, and not to deepen and expand their knowledge of the subject.

\section{Conclusions}

The results of the study confirm the hypothesis put forward that teachers, for one reason or another, are not ready to use innovative productive methods in their pedagogical activity. Although the educational process and scientific discourse are oversaturated with arguments about innovative, modern, effective and most productive methods of teaching and upbringing, when the specific question of choosing a method is presented to professionals, they opt for more conservative and familiar methods.

These studies do not allow making unambiguous conclusions about what factors influence this situation: personal life experience; the inertia of the system of inheritance and selection of innovations that lose in a competitive clash with tradition; quality, content or methods of teaching future teachers. However, it is obvious that the existing system of teacher training does not create the necessary conditions for the introduction of innovative productive methods into their future practice, which leads to conservatism in the pedagogical sphere, which in turn does not contribute to the renewal and modernization of the system as a whole.

Russian education is in a closed cycle of reproduction of conservative teaching methods and technologies, which significantly reduces the effectiveness of modernizing this area. Researchers are faced with the tasks of a detailed study of the factors that prevent the introduction of innovative technologies, methods and approaches into pedagogical practice, and the search for opportunities for a quick but painless optimization of the system.

\section{References}

1. E. A. Lysova, et al., Digital modernization of the region's educational market and its influence on quality of education, International Journal for Quality Research, 14(1), 253-270 (2019) doi: 10.24874/IJQR14.01-16

2. L. S. Cheglakova, et al., Marketing strategy of quality management during reorganization of regional universities in the process of modernization of education in the conditions of region's transition to industry 4.0, International Journal for Quality Research, 14(1), 33-50 (2019) doi: 10.24874/IJQR14.01-03

3. R. S. Nagovitsyn, et al., Modernization of Regional Continuing Pedagogical Education in the «School-College-Institute». European Journal of Contemporary Education, 8(1), 144-156 (2019) doi: 10.13187/ejced.2019.1.144

4. L. A. Abramova, Participating in the project on the modernization of Russian pedagogical education, European Proceedings of Social and Behavioural Sciences (IFTE 2017 - 3rd international forum on teacher education), 29, 1-4 (2017) doi: http://dx.doi.org/10.15405/epsbs.2017.08.02.1 
5. A. Batyrbekova, et al., Evaluation of the System of Methodical Training of a Physics Teacher in the Conditions of Modernization of Education. European Journal of Contemporary Education, 9(1), 4-18 (2020) doi: 10.13187/ejced.2020.1.4

6. S. B. Kvesko, et al., Educational robotics as an Innovative teaching practice using technology: minimization of risks. IOP Conference Series: Materials Science and Engineering (2nd International Conference on Cognitive Robotics), 363 (2018) doi:10.1088/1757-899X/363/1/012004

7. V. P. Zeleeva, F. L. Ratner, Influence of socio-cultural conditions on modernization of communicative models in teacher education, European Proceedings of Social and Behavioural Sciences (4th International Forum on Teacher Education (IFTE)), 45, 302-309 (2018) doi: 10.15405/epsbs.2018.09.35

8. I. N. Dobrotina, E. L. Erokhina, Paradigm of the student-teacher relationship in the modern educational environment, SHS Web of Conferences (International Conference on Education Environment for the Information Age (EEIA)), 29 (2016) doi: 10.1051/shsconf/20162901017

9. E. S. Anichkin, K. E. Kovalenko, Modernización de la educación superior en los países Asiáticos centrales: tendencias, problemas y soluciones, Holos, Ano, 36(1) (2020) doi: 10.15628/holos.2020.7626

10. K. Ren, Y. Bai, Research on Innovative Methods of College Students' Sports Teaching Based on Internet Education Technology. Educational Sciences: Theory \& Practice, 18(5), 2486-2493 (2018) doi: 10.12738/estp.2018.5.149

11. G. A. Toto, Effects and Consequences of Media Technology on Learning and Innovative Educational Strategies. Online Journal of Communication and Media Technologies, 9(1) (2019) doi: 10.29333/ojcmt/3988

12. A. Lefstein, et al., Relocating Research on Teacher Learning: Toward Pedagogically Productive Talk. Educational researcher, 49(5), 360-368 (2020) doi: 10.3102/0013189X20922998

13. K. Chusinkunawut, et al., Design-based science with communication scaffolding results in productive conversations and improved learning for secondary students. Research in science education (2020) DOI: 10.1007/s11165-020-09926-w

14. Y. Qin, A Study of Theories and Practice of Sports Teaching Methods Based on Creative Education Concept. Agro food industry hi-tech, 28(1), 3023-3025 (2017) URL: https://www.teknoscienze.com/tks issue/vol_281/ (Last accessed 11.06.2020)

15. J. Bremholm, et al., Student work and the multimodal challenge. A mixed methods study of students' productive work in L1, science and mathematics. L1 educational studies in language and literature, 18 (2018) doi: 10.17239/L1ESLL-2018.18.01.12

16. A. Gauthier, J. Jenkinson, Serious Game Leverages Productive Negativity to Facilitate Conceptual Change in Undergraduate Molecular Biology: A Mixed-Methods Randomized Controlled Trial. International Journal of Game-Based Learning, 7(2) (2017) doi: 10.4018/IJGBL.2017040102

17. N. Steenhof, et al., Productive failure as an instructional approach to promote future learning. Advances in health sciences education, 24(4), 739-749 (2019) doi: 10.1007/s10459-019-09895-4

18. J. Sullins, et al., Not all confusion is productive: an investigation into confusion induction methods and their impact on learning. International journal of learning technology, 14(4), 288-303 (2019) doi: 10.1504/IJLT.2019.106552 